\title{
Biogenic Synthesis of Silver Nanoparticles with Antimicrobial Properties
}

\section{Lagopati $\mathrm{N}^{1,2}$, Gatou MA ${ }^{1}$, Tsoukleris DS ${ }^{1}$, Pavlatou EA ${ }^{1 *}$}

${ }^{1}$ Laboratory of General Chemistry, School of Chemical Engineering, National Technical University of Athens, Zografou Campus, Iroon Polytechniou str, Zografou, Athens, Greece

${ }^{2}$ Laboratory of Histology-Embryology, Molecular Carcinogenesis Group, Faculty of Medicine, School of Health Science, National and Kapodistrian University of Athens, Micros Asias Str, Goudi, Athens, Greece

\section{Review Article}

Volume 5 Issue 1

Received Date: January 29, 2020

Published Date: July 03, 2020

DOI: $10.23880 /$ nnoa-16000185

*Corresponding author: Evangelia A Pavlatou, Laboratory of General Chemistry, School of Chemical Engineering, National Technical University of Athens, Zografou Campus, Iroon Polytechniou str, Zografou, Athens, Greece, Email: pavlatou@mail.ntua. gr

\section{Abstract}

The transmission of a wide range of diseases, related to the infection by pathogenic microorganisms is a major public health problem that daily endangers the safety of human population. Silver has been thoroughly studied and used against bacteria due to its antimicrobial properties. Nanostructured silver gathers all the advantages of the silver itself, as well as the advanced performance of the nanomaterials. Thus, currently, silver nanoparticles constitute the most widely used kind of nanoparticles in biomedicine, due to their attractive antimicrobial properties. A variety of physical and chemical methods are employed for the AgNPs synthesis. However, many of them include the use of toxic reagents or require large amounts of energy, during the synthesis process. For this reason, many eco-friendly methods are proposed in order to synthesize AgNPs. Hence, biogenic synthesis of AgNPs, utilizing biological resources opens a novel route for the development of alternative production processes. These methods seem to have significant advantages, as the extracts contribute positively to the formation and enhancement of the antimicrobial activity of AgNPs, also acting as protective agents of the produced particles. In this review an integrated approach of AgNPs bio-synthetic methods using microorganisms, such as bacteria and fungi, plants and plant extracts, as well as several templates, like DNA and viruses is discussed, shedding light on the comparative advantages of them.

Keywords: Silver Nanoparticles; Antibacterial Properties; Biosynthesis; Biogenic Synthesis; Green Synthesis; Microorganisms; Plant Extracts; Templates

\section{Introduction}

Nowadays, the uncontrolled spread of diseases and infections caused by various pathogenic agents is a major public health problem [1]. Particularly, the microbial resistance opposed to a wide range of microbes, is one of the most crucial issues in the field of medicine [2]. Thus, in the light of the aforementioned issues and thanks to the recent advances in science and technology worldwide, which have led to the growth of nanotechnology, these problems may be controlled [3]. Nanotechnology is emerged as a promising interdisciplinary section dealing with research and development in various fields [4] and is currently considered to be a powerful medical tool, consisting a separate branch, called nanomedicine [5].

Within that framework, during the last decade, a new 
concept has been introduced, that of biogenic nanotechnology [6]. Biogenic nanotechnology constitutes an area of interest with important objective of facilitating the production of nanomaterial, such as metal nanoparticles [7]. Typically, MNPs can be synthesized using various approaches, such as biological, physical, or chemical methods with the conditions to control the size/shape and stability of nanoparticles [8]. The biogenic synthesis development of MNPs involves the use of non-toxic chemical substances, such as solvents, reducing and stabilizing agents $[9,10]$. Thus, apart from the non-toxic nature of the process, the simple development design and the cost effectiveness are the distinctive advantages of biogenic synthesis of MNPs, over the physical and chemical synthesis methods [11]. Biogenic methods of synthesis are performed through intracellular or extracellular approaches, generally utilizing plants and microorganisms [12]. The MNPs which are synthesized through a biogenic method, display multiple applications in fields such as catalysis, agriculture and electronics, with eminent that of biomedicine[13,14], with reported studies focusing on cancer treatment targeted drug delivery, DNA analysis, gene therapy, antibacterial agents, magnetic resonance imaging, enhancing reaction rates, and biosensors $[15,16]$.

Silver has been thoroughly studied and used to treat bacterial infections due to its antimicrobial potential [17]. Silver nanoparticles gather all the advantage of the silver itself, as well as the advanced performance of the nanomaterials [18]. Thus, among the other noble MNPs, AgNPs possess potent antibacterial, antiviral and anticancer properties [19-21]. Additionally, AgNPs are utilized for biosensing, coating surgical instruments, water treatment, etc [22-26].

The promising antimicrobial properties of AgNPs against both gram-positive and gram-negative bacterial cells and their stability have attracted the interest of a great part of the scientific society [27]. It seems that the use of AgNPs, leads the bacterial cells to be less prone to develop antibacterial resistance [28].

Numerous strategies for the synthesis of AgNPs have been developed, including a variety of physical and chemical methods [29]. However, as mentioned above, the majority of them either employs toxic compounds or requires large amounts of energy during the synthesis process [30]. Under such circumstances, the elaboration of biogenic methods based on plants, fungi and bacteria has proven to be extremely promising for the AgNPs production, without negative impact on human health and the environment [31]. These methods seem to have significant advantages, as the extracts contribute positively to the formation and enhancement of the antimicrobial activity of AgNPs, also acting as protective agents of the produced particles [32].

In the current manuscript, we provide an overview of the preparation of AgNPs with antimicrobial properties, using biogenic methods, highlighting the great impact of the incorporation of green chemistry in innovative research protocols.

\begin{tabular}{|c|c|c|}
\hline Physical & Chemical & Biological \\
\hline Ball-milling & Chemical & \\
Arc-discharge & reduction & Electrochemical \\
Vapor & Microorganisms \\
condensation & $\begin{array}{c}\text { Pyrolysis } \\
\text { Irradiation- } \\
\text { Laser ablation }\end{array}$ & $\begin{array}{c}\text { Templates } \\
\text { assisted }\end{array}$ \\
\end{tabular}

Table 1: Methods for the synthesis of AgNPs.

\section{Biogenic Synthesis of Silver Nanoparticles}

Since the conventional methods for the synthesis of AgNPs utilize toxic and non-environmentally friendly reagents [33,34], researchers worldwide were triggered to develop and optimize the biogenic synthesis as a new route for the production of AgNPs $[35,36]$. Three main categories of biogenic synthesis of AgNPs would be determined, the synthesis based on the utilization of microorganisms, such as fungi and bacteria [37], the green synthesis, based on the use of plants and their extracts [38] and the approach which applies templates, such as viruses, membranes and DNA $[39,40]$.

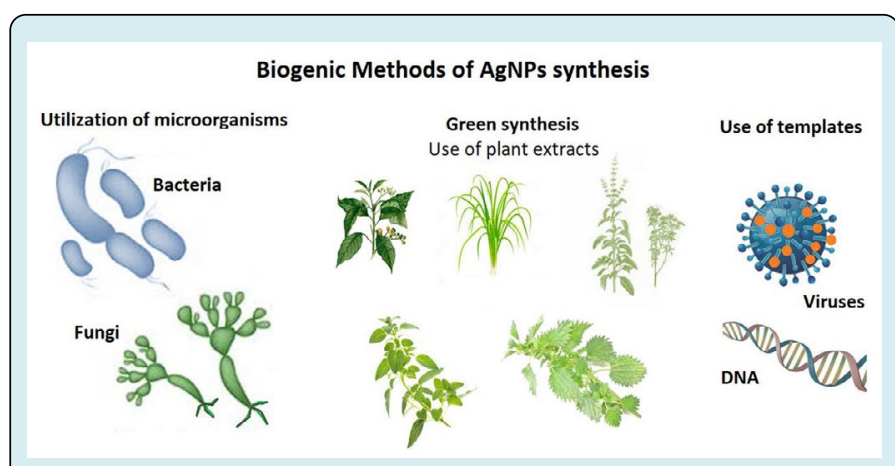

Figure 1: The main biogenic methods of AgNPs synthesis.

\section{Synthesis of AgNps Using Microorganisms}

The potential of microorganisms, like fungi and bacteria, acting as human, eco-friendly precursors for the production of AgNPs with antimicrobial properties, has gained a lot of interest [41-45]. The use of these microorganisms as bio-factories gathers several advantages, such as the 
production of nanoparticles with various sizes and chemical compositions in a mono-disperse way $[46,47]$.

Researchers have focused on prokaryotes as a mean for producing AgNPs, since they are characterized by some significant virtues, such as abundance and adaptation to extreme conditions, low cost for cultivation, fast growth and growth conditions like temperature, oxygenation and incubation time can be easily controlled [48-52]. In addition, bacteria constitute efficient bio-factories for the synthesis of AgNPs, as they produce many extra- and intracellular inorganic materials [53]. Generally, AgNPs can be synthesized by bacteria through bioreduction, in which the reductase enzymes reduce $\mathrm{Ag}+\mathrm{ions}$, commonly obtained by the addition of $\mathrm{AgNO}_{3}$, resulting to AgNPs. This reaction can be held either in the intracellular or in the extracellular environment, depending on the location of the reduction of the Ag cations [54].

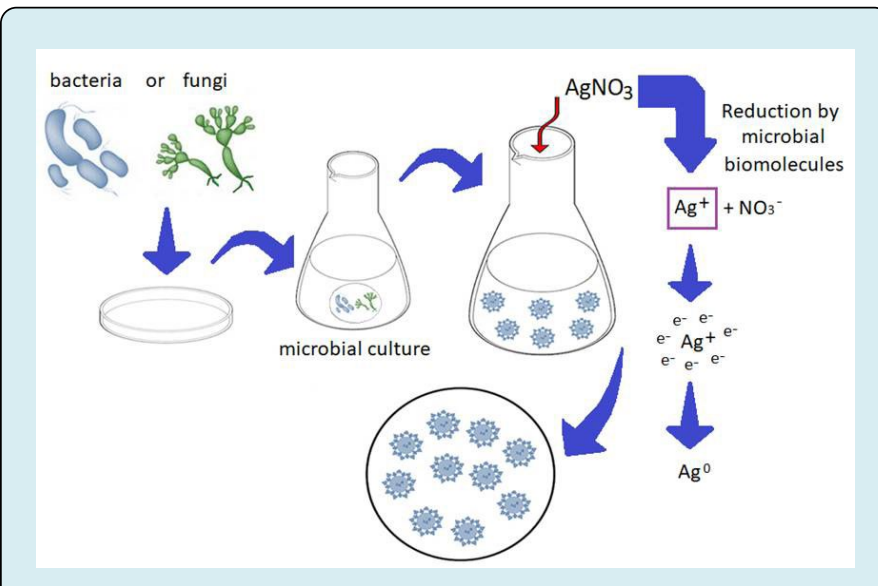

Figure 2: AgNPs synthesis through bacteria or fungi bioreduction.

The first reported attempt to synthesize AgNPs by bacteria was made using Pseudomonas stutzeri, which was isolated from a silver mine [55-58]. In general, it is known that AgNPs are toxic to bacteria; thus, these bio-factories can become resistant to these nanoparticles through the incorporation of the "sil" gene using plasmids [59,60]. However, Pseudomonas stutzeri is mainly resistant to silver, owing this property to the intracellular buildup of silver crystals of about $200 \mathrm{~nm}$ in diameter and of a certain shape and composition [61-65].

Otari, et al. [66] investigated the synthesis of AgNPs using Rhodococcus spp. Specifically, they reported that the AgNPs synthesis was carried out after $10 \mathrm{~h}$ of incubation at room temperature, while the produced nanoparticles were spherical, having a mean diameter of about 10-12 nm. The synthesized AgNPs were also tested regarding their antimicrobial activity and they demonstrated remarkable both bactericidal and bacteriostatic activity against a wide range of bacteria, such as Escherichia coli, Enterococcus faecalis , Staphylococcus aureus, Klebsiella pneumoniae, Pseudomonas aeruginosa, Acinetobacter baumannii and Proteus vulgaris $[67,68]$.

Moreover Wang, et al. [69] performed synthesis of AgNPs in the culture supernatant of Bacillus methylotrophicus. The aforesaid nanoparticles were produced at $28^{\circ} \mathrm{C}$ within $48 \mathrm{~h}$ and their antimicrobial activity was tested against E. coli, Candida albicans, Salmonella enterica and Vibrio parahaemolyticus [70]. These AgNPs presented a better inhibition growth compared to antibiotics. The main drawback related to the AgNPs synthesis using bacteria is the limited variety of sizes and shapes of the produced nanoparticles [71].

The biogenic approach using fungi for the synthesis of nanoparticles has been well recognized, because of the Eukaryota have various documented and remarkable characteristics [72]. Generally, fungi can be used as excellent resources of a wide variety of extracellular enzymes for the synthesis of different MNPs, including AgNPs [73,74]. The fungal materials used in the synthesis of MNPs, include polysaccharides, proteins, mycelia and fruiting bodies. Fungi not exposed to a large concentration of metals possess an inherent ability to produce higher concentrations of proteins, in comparison to bacteria, which contributes to metal reduction $[75,76]$.

Conducted synthesis of AgNPs in the culture supernatants of Aspergillus terreus [77]. The NPs were poly-dispersed with a mean diameter ranging from 1 to $10 \mathrm{~nm}$, while the synthesis was facilitated by an extracellular enzyme [78]. Li, et al. [79]. have also reported the extracellular synthesis of AgNPs at room temperature using Aspergillus terreus. In addition, these NPs presented high antimicrobial activity over a wide variety of pathogenic microorganisms. Recently, Seetharaman used Phomopsis liquidambaris for the synthesis of AgNPs [80]. Specifically, the produced NPs were characterized by a spherical shape and a mean size equal to $18.7 \mathrm{~nm}$. These NPs were also act effectively both as antimicrobial and mosquitocidal agents. Recently, showed the reduction of silver ions by phenolic compound homogentisic acid, presented in the aqueous extract obtained from Lactarius piperatus mushroom [81].

Macrofungi is another category of fungi that includes edible and medicinal mushrooms growing on organic substrates in nature [82]. Nowadays, many studies focus on synthesizing MNPs, using different genera of edible and medicinal mushrooms, due to the innumerable bioactive compounds with diverse biological activities that are 
present within them [83]. A quite wide variety of amino acids, proteins and polysaccharides that are present in the mushrooms have been utilized in both the intracellular and extracellular synthesis of MNPs, including AgNPs [84]. The aforementioned compounds found in the mushrooms result to the synthesis of NPs with high stability and good dispersion [85]. According to Owaid, the mushroom-assisted synthesis method has led to the mycosynthesis of AgNPs [86]. The term mycosynthesis is used to describe the biosynthesis of MNPs by extracts of edible and medicinal mushrooms or extracts of fungi in general as bioreducers and stabilizers, instead of other biomaterials $[87,88]$.

Oyster mushroom Pleurotus sp. has been used to mycosynthesize AgNPs. Pleurotus sp. constitutes one of the well-known edible and medicinal mushrooms that has antimicrobial, antibacterial, antifungal, anti-candidal, antiviral, anti-cancer and anti-diabetic properties [89].

The first attempt to mycosynthesize AgNPs was made by the scientific group of Vigneshwaran [90]. The AgNPs synthesis included the use of spent mushroom substrate proteins, which contained fungal mycelia and fruiting bodies residues of oyster mushroom. After that, many studies were conducted using extracts of different oyster mushroom species [91]. The AgNPs biosynthesized using oyster mushroom species were applied against bacteria in vitro and showed excellent antibacterial efficacy [55].

\section{Synthesis of Agnps Using Plants}

Plant-based synthesis of MNPs, also known as green synthesis, constitutes one of the emerging fields of nanotechnology in the recent era [92]. It is widely acknowledged way of NPs development, because of the plentiful and diversified cellular metabolites present in plant extracts. These bioactive metabolites are capable to act both as reducing and capping agents, thus eliminating the need to add any further chemical agent to synthesize the nanoparticles [61-65].

Thus, AgNPs can be prepared with a biogenic composition, using aqueous extracts of natural raw materials, such as oregano, nettle, propolis and various others, as reducing agents [93]. Plant extracts are rich in different chemical compounds, such as polyphenols, flavonoids, fatty acids, that make them a potential candidate to be used as a green reducing and stabilizing agent for the synthesis of MNPs. The methods for the AgNPs synthesis based both on plants and their extracts are non-pathogenic, simple and characterized by a higher bio-reduction potential, compared to microbial culture filtrates. Several researchers have reported the AgNPs synthesis with antimicrobial properties using plants [42-49].
AgNPs can be synthesized using either the whole plant or its extract; thus the availability of the reducing and stabilizing agents is greater in their extract than in the plant itself, so as a result the majority of the studies have focused on the use of plant extracts for the AgNPs synthesis [72]. In general, the plant-based method for the production of AgNPs involves the stage of mixing each of plant extract, which is selected, with an aqueous solution of $\mathrm{AgNO}_{3}$. The synthesis process takes place at room temperature and lasts from several minutes to a few hours to be completed [94]. The principal mechanism responsible for the production of silver nanoparticles is based on the reduction process that is controlled by phytochemicals, such as terpenoids, flavones, ketones, aldehydes, quinones, amines and carboxylic acids. In particular, flavones, quinones and organic acids are in charge of the immediate reduction of the $\mathrm{Ag}^{+}$ions.

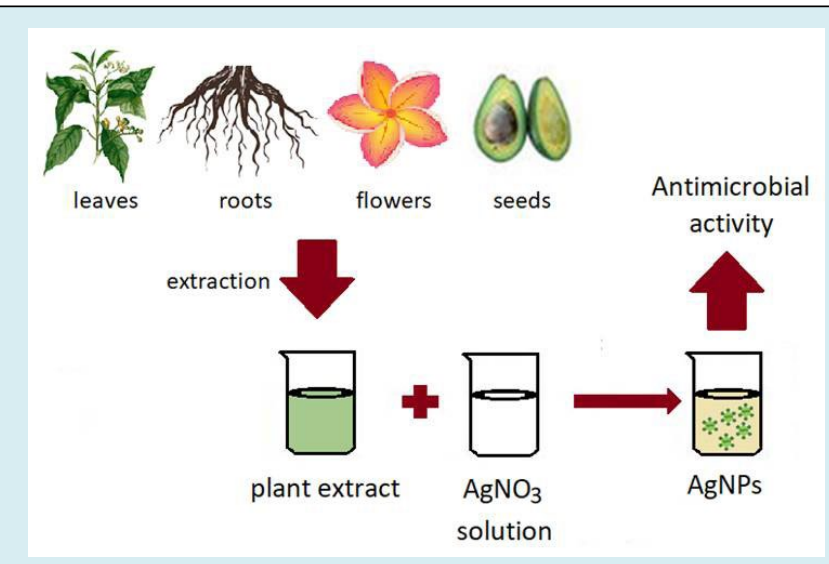

Figure 3: Green synthesis of AgNPs via plant extraction.

According to Veerasamy and his colleagues, the extract from the leaves of Garcinia mangostana led to the biosynthesis of AgNPs characterized by an adequate antimicrobial activity. Prabu and Johnson used the leaf extracts of Solanum verbascifolium, Tylophora ovata, Cymbopogon citronella and Tragia involucrate, in order to synthesize AgNPs via a green method. The formation of AgNPs was observed within $15 \mathrm{~min}$, while the results of the several characterization techniques revealed that the produced NPs were of high stability and had no impurities.

Another study for the green synthesis of AgNPs using plant extracts was conducted by the group of Ahmed, who used Azadirachta indica aqueous leaf extracts. Only 15 min were required for the conversion of silver ions into AgNPs at room temperature, without the involvement of any hazardous chemical. The produced AgNPs showed antibacterial properties against both gram positive and gram negative microorganisms [95]. 
Investigated a green, efficient and sustainable route for the AgNPs synthesis using aqueous $\mathrm{AgNO}_{3}$ solution and leaf extracts of three plants, Musa balbisiana, Azadirachta indica and Ocimum tenuiflorum, which are well known for their wide availability and medicinal applications. AgNPs obtained showed significantly higher antimicrobial properties against E. coli and Bacillus sp. in comparison to both $\mathrm{AgNO}_{3}$ and raw plant extracts. Furthermore, de Aragão, et al. [96] biosynthesized AgNPs using as reducing and stabilizing agent a polysaccharide extracted from red algae Gracilaria birdiae, present in the coast of Pique [35-38]. The AgNPs were tested for antimicrobial activity using E. coli and $S$. aureus and all samples showed antimicrobial properties.

Good antibacterial performance against common pathogens presented also the AgNPs produced by Ahmad, et al. [42] using Desmodium triflorum extract. The AgNPs when combined with antibiotics presented synergic effect in suppressing the growth of bacteria [97]. Have successfully biosynthesized AgNPs using aqueous leaves extract of Guiera senegalensis. The prepared AgNPs showed excellent bactericidal effect against E. coli and $S$. aureus with about $99 \%$ colony reduction yield.

Synthesized AgNPs by Crocus haussknechtii extract, which showed strong inhibitory effect against both $S$. aureus and $P$. aeruginosa. Also, Hernández-Morales and colleagues reported for the first time the green synthesis of AgNPs using extracts of two varieties of Salvia hispanica seeds. The antibacterial study indicated that the prepared AgNPs have powerful antimicrobial activity against $E$. coli and $S$. aureus. Biosynthesized silver nanoparticles using babassu mesocarp starch. Starches have mainly been used in nanobiotechnology in the development of MNPs, due to their reduction and stabilization capacities [98]. The biosynthesized AgNPs showed an antimicrobial effect against $S$. aureus and $E$. coli, resulting in notable membrane damage. Recently, Sharma et al. reported Coptidis rhizome eco-friendly ex-situ biosynthesis of AgNPs with antimicrobial potential against both Gram-positive and Gram-negative microorganisms. Coptidis rhizome has been known for its medicinal properties, due to the existence of berberine, coptisine, jatrorrhizine and palmatine $[99,100]$.

Finally, reported a green, facile and highly efficient process for the preparation of AgNPs using Crataegus pentagyna fruit extracts as reducing and capping agent. Crataegus spp. constitutes one of the oldest medicinal plants that are extensively employed throughout the world, mainly in Turkey and South Europe. Crataegus spp. is primarily employed for the treatment of cardiovascular deseases, while Crataegus extract contains phenolic and flavonoid compounds that exhibit antioxidant activity. The so-produced NPs presented efficient antimicrobial activity against $S$. aureus, E. faecalis, $P$. aeruginosa, A. baumanii and
E. coli.

\section{Synthesis of AgNPs Using Templates}

During the last years, the use of viruses as templates for the synthesis of AgNPs have been studied, as they offer confined cages, high symmetry, functional protein capsids and unique architecture structure, except for the easy manipulation [101]. Furthermore, viral scaffolds can stimulate both the nucleation and assembly of inorganic materials. Some examples of viral components are tobacco mosaic virus and cowpea chlorotic mottle virus [102].

Biopolymers, such as DNA, proteins and polysaccharides, have the advantage of availability in a wide variety of sources and thus have great potential to be used as a template in synthesis of other materials. By means of inducing the biomineralization of inorganic NPs, biopolymers can synthesize nanomaterials that have certain structures, like gold NPs and Tin Oxide $[99,100]$. Peptides are utilized as a frame for the synthesis of AgNPs. Kashmery has described the synthesis of sugar-modified peptides to template the synthesis of AgNPs using Tollens' reagent. He correlated the quantity of sugar units and the size of AgNPs. Furthermore, he proposed a novel template-directed triazole ligand strategy for the synthesis of AgNPs.

DNA has been also used as template for the synthesis of AgNPs. Davis and co-researchers reported that a nucleoprotein filament from polymerizing RecA proteins on a single strand DNA probe was mixed with a long aldehydederived double strand DNA substrate [103]. Afterwards, the sample was exposed to $\mathrm{AgNO}_{3}$ ions which binded to DNA, when RecA proteins were absent; so, the aldehyde groups reduced the $\mathrm{Ag}^{+}$ions to $\mathrm{Ag}^{0}$ resulting to the formation of silver nanoparticles $[99,100]$.

\section{AgNPs in Chemical Doping}

Since AgNPs are one of the most vital and fascinating nanomaterials among several MNPs that are involved in biomedical applications, it is reasonable that they are selected for the development of advanced composite materials. Studied the anticandidal properties of AgNPs embedded mesoporous silicon dioxide nanospheres, indicating very promising results [104]. Developed a novel green biomimetic approach for synthesis of zinc oxide/silver nanocomposites with antimicrobial activity against food-borne pathogens. Nguyen et al. also focused on the antibacterial activity of both titanium dioxide and $\mathrm{ZnO}$ decorated with AgNPs [105]. Various conventional methods of AgNPs synthesis include the use of toxic reagents or require large amounts of energy. For this reason, biogenic synthesis AgNPs in order to be used for chemical doping or binding to other nanomaterials 
should be selected. For instance, Su et al., developed AgNPs/ N-Doped Carbon-Dots nanocomposites, derived from Siraitia Grosvenorii, focusing on their surface-enhanced characteristics. He proposed a green-synthesized system based on AgNPs encapsulated on nitrogen-doped graphene, for hydrogen peroxide detection. Ruíz-Baltazar exploited the extracts from Mellissa officinalis in order to apply a novel biosynthesis method of AgNPs embedded to hydroxyapatite for dental and orthopedic applications [106]. The increasing interest for eco-friendly techniques and processes indicates the impact of their advantages.

\section{$\mathrm{TiO}_{2}$ Doped with AgNPs Produced via Biogenic Methods}

Recently, important scientific effort is observed in the field of chemical doping of $\mathrm{TiO}_{2}$ in order to be utilized in environmental, antimicrobial, anticancer and other biomedical applications. He achieved the green synthesis of AgNPs and $\mathrm{TiO}_{2} \mathrm{NPs}$ using Euphorbia prostrata extracts, showing shift from apoptosis to $G_{0} / G_{1}$ arrest, followed by necrotic cell death in Leishmania donovani. Synthesized Ag$\mathrm{TiO}_{2}$-G photocatalysts with an innovative and ecofriendly method by pranus cerasus, in order to investigate the effect in photodegradation of organic pollutants in water and showed that this composite material presented higher photocatalytic performance in the photodegradation [107]. Created by green process a system based on $\mathrm{Ag}_{-} \mathrm{TiO}_{2} \mathrm{NPs}$ bound on porous glass, presenting enhanced photocatalytic performance for oxidative desulfurization and removal of dyes under visible light [108]. Hariharan reported that green hydrothermal synthesis of $\mathrm{Ag}^{-\mathrm{TiO}_{2}} \mathrm{NPs}$ led to enhanced photocatalytic and anticancer properties [109]. They developed $\mathrm{TiO}_{2}-\mathrm{Ag}$ nanocomposites, via green route, for dye degradation, possessing significant antimicrobial potential [110-116]. Recently, our group focused on the green synthesis of AgNPs, which are then bound to chemically doped $\mathrm{TiO}_{2} \mathrm{NPs}$ with nitrogen, and embedded in a metallic matrix, employing pulsed electrodeposition. The preparation of AgNPs was achieved by the extractions of natural raw materials, such as origin and nettle, because these herbs contain bioactive phenolic compounds with antioxidant and antimicrobial properties, acting as reducing agents and as stabilizers, preventing from the formation of NPs aggregations [117]. The combination of $\mathrm{AgNP}_{\mathrm{s}}$ and $\mathrm{N}-\mathrm{TiO}_{2} \mathrm{NPs}$ leads to the synthesis of hybrid systems with improved photocatalytic and antimicrobial properties. These composites can be stabilized on metal surfaces, with strong mechanical properties in order to be used in multifunctional every-day-touched surfaces.

\section{Conclusion and Future Perspectives}

AgNPs constitute perhaps the mostly used kind of
NPs in biomedical research, due to their antimicrobial properties. A variety of physical and chemical methods are employed for the AgNPs synthesis. However, many of them include the use of toxic reagents or require large amounts of energy. For this reason, biogenic methods are proposed instead of the conventional methods of AgNPs synthesis. Three main categories of biogenic synthesis of AgNPs would be determined, the synthesis based on the utilization of microorganisms, the green synthesis, based on the use of plants and their extracts and the approach which applies templates and scaffolds. These methods utilize biological resources, as reducing agents and seem to have significant advantages, since the extracts contribute positively to the formation and enhancement of the antimicrobial activity of AgNPs. Overall, in this review, an integrated approach of AgNPs bio-synthetic methods using microorganisms, such as bacteria and fungi, plants and plant extracts, as well as several templates, like DNA and viruses was discussed, in order to highlight the significance of the incorporation of green chemistry in basic and applied research.

\section{Acknowledgments}

«This research is implemented through IKY scholarships program and co-financed by the European Union and Greek national funds through the action entitled "Reinforcement of Postdoctoral Researchers", in the framework of the Operational Program "Human Resources Development Program, Education and Lifelong Learning" of the National Strategic Reference Framework 2014 - 2020 - MIS5001552».

\section{Conflicts of Interest}

The authors declare no conflict of interest.

\section{References}

1. Ahmad S, Munir S, Zeb N, Ullah A, Khan B, et al. (2019) Green nanotechnology: a review on green synthesis of silver nanoparticles - an ecofriendly approach. International journal of nanomedicine 14: 5087-5107.

2. Ahmad N, Sharma S, Alam MK, Singh VN, Shamsi SF, et al. (2010) Rapid synthesis of silver nanoparticles using dried medicinal plant of basil. Colloids and Surfaces B: Biointerfaces 81(1): 81-86.

3. Ahmed S, Ahmad M, Swami BL, Ikram S (2016) A review on plants extract mediated synthesis of silver nanoparticles for antimicrobial applications: A green expertise. Journal of Advanced Research 7(1):17-28.

4. Akbari M, Aetemady A, Firoozeh F, Yaseliani M (2017) Synthesis of AgO-TiO2 nanocomposite through a simple method and its antibacterial activities. Journal of 
Materials Science Materials in Electronics 28: 11562.

5. Al-Bahrani R, Raman J, Lakshmanan H, Hassan AA, Sabaratnam V (2017) Green synthesis of silver nanoparticles using tree oyster mushroom Pleurotus ostreatus and its inhibitory activity against pathogenic bacteria. Materials Letters 186: 21-25.

6. Amerasan D, Thiyagarajan N, Murugan K, Madhiyazhagan P, Panneerselvam C, et al. (2015) Myco-synthesis of silver nanoparticles using Metarhizium anisopliae against the rural malaria vector Anopheles culicifacies Giles . Journal of Pest Science 89: 249-256.

7. Araruna FB, Araruna FAO, Lima Alves Pereira LP, Aranha Brito MC, Veras Quelemes P, et al. (2020) Green syntheses of silver nanoparticles using babassu mesocarp starch and their antimicrobial applications. Environmental Nanotechnology Monitoring and Management 13: 100281.

8. Banerjee $\mathrm{P}$, Satapathy $\mathrm{M}$, Mukhopahayay A, Das $\mathrm{P}$ (2014) Leaf extract mediated green synthesis of silver nanoparticles from widely available Indian plants: synthesis, characterization, antimicrobial property and toxicity analysis. Bioresources and Bioprocessing 1 : 1-10.

9. Bello BA, Khan SA, Khan JA, Syed FQ, Anwar Y, et al. (2017) Antiproliferation and antibacterial effect of biosynthesized AgNPs from leaves extract of Guiera senegalensis and its catalytic reduction on some persistent organic pollutants. Journal of Photochemistry \& Photobiology B: Biology 175: 99-108.

10. Beyene HD, Werkneh AA, Bezabh HK, Ambaye TG (2017) Synthesis paradigm and applications of silver nanoparticles, a review. Sustainable Materials and Technologies 13: 18-23.

11. Bhakya S, Muthukrishnan S, Sukumaran M, Muthukumar M (2015) Biogenic synthesis of silver nanoparticles and their antioxidant and antibacterial activity. Applied Nanoscience 6: 755-766.

12. Boroumand MA, Namvar F, Moniri M, Md Tahir P, Azizi S, et al. (2015) Nanoparticles Biosynthesized by Fungi and Yeast: A Review of Their Preparation, Properties, and Medical Applications. Molecules 20(9): 16540-16565.

13. Burdușel AC, Gherasim O, Grumezescu AM, Mogoantă L, Ficai A, et al. (2018) Biomedical Applications of Silver Nanoparticles: An Up-to-Date Overview. Nanomaterials 8(9): 681.

14. Calderón-Jiménez B, Johnson ME, Montoro Bustos
AR, Murphy KE, Winchester MR, et al. (2017) Silver Nanoparticles: Technological Advances, Societal Impacts, and Metrological Challenges. Frontiers in chemistry 5: 6 .

15. Chaudhuri KS, Chandela S, Malodia L (2016) Plant mediated green synthesis of silver nanoparticles using Tecomella undulata leaf extract and their characterization. Nano Biomedicine and Engineering 8: 1-8.

16. Chaturvedi VK, Agarwal S, Gupta KK, Ramteke PW, Singh MP (2018) Medicinal mushroom: boon for therapeutic applications. 3 Biotech 8: 334.

17. Chen Y, Shen C, Wang J, Xiao G, Luo G (2018) Green Synthesis of Ag-TiO2 Supported on Porous Glass with Enhanced Photocatalytic Performance for Oxidative Desulfurization and Removal of Dyes under Visible Light. ACS Sustainable Chem Eng 6: 13276-13286.

18. Cheviron P, Gouanvé F, Espuche E (2014) Green synthesis of colloid silver nanoparticles and resulting biodegradable starch/silver nanocomposites. Carbohydrate Polymers 108: 291-298.

19. Das RK, Pachapur VL, Lonappan L, Naghdi M, Pulicharla $R$, et al. (2017) Biological synthesis of metallic nanoparticles: plants, animals and microbial aspects. Nanotechnol Environ Eng 2: 18.

20. De Aragão AP, de Oliveira TM, Quelemes PV, Perfeito MLG, Araújo MC, et al. (2019) Green synthesis of silver nanoparticles using the seaweed Gracilaria birdiae and their antibacterial activity. Arabian Journal of Chemistry 12(8): 4182-4188.

21. Dhillon GS, Brar SK, Kaur S, Verma M (2012) Green approach for nanoparticles biosynthesis by fungi: Current trends and applications. Critical Reviews in Biotechnology 32: 49-73.

22. Dinesh D, Murugan K, Madhiyazhagan P, Panneerselvam C, Kumar PM, et al. (2015) Mosquitocidal and antibacterial activity of green-synthesized silver nanoparticles from Aloe vera extracts: towards an effective tool against the malaria vector Anopheles stephensi? Parasitology Research 114(4): 1519-1529.

23. Du L, Xu Q, Huang M, Xian L, Feng JX (2015) Synthesis of small silver nanoparticles under light radiation by fungus Penicillium oxalicum and its application for the catalytic reduction of methylene blue. Materials Chemistry and Physics 160: 40-47.

24. Dubey SP, Lahtinen M, Sillanpaa M (2016) Tansy fruit mediated greener synthesis of silver and gold 
nanoparticles. Process Biochemistry 45: 1065-1071.

25. Ebrahimzadeh MA, Naghizadeh A, Amiri O, ShirzadiAhodashti M, Mortazavi-Derazkola S (2020) Green and facile synthesis of $\mathrm{Ag}$ nanoparticles using Crataegus pentagyna fruit extract for organic pollution dyes degradation and antibacterial application. Bioorganic Chemistry 94: 103425.

26. Ebrahimzadeh MA, Khalili M, Jafari N, Zareh G, Farzin D, et al. (2018) Antihypoxic activities of Crataegus pentaegyn and Crataegus microphylla fruits-an in vivo assay. Brazilian Journal of Pharmaceutical Sciences 54: 17363.

27. Elamawi RM, Al-Harbi RE, Hendi AA (2018) Biosynthesis and characterization of silver nanoparticles using Trichoderma longibrachiatum and their effect on phytopathogenic fungi. Egypt J Biol Pest Control 28: 28.

28. Elkhateeb WA, Daba GM, Thomas PW, Wen TC (2019) Medicinal mushrooms as a new source of natural therapeutic bioactive compounds. Egypt Pharmaceut J 18: 88-101.

29. Elbeshehy EKF, Elazzazy AM, Aggelis G (2015) Silver nanoparticles synthesis mediated by new isolates of Bacillus spp., nanoparticle characterization and their activity against Bean Yellow Mosaic Virus and human pathogens. Frontiers in Microbiology 453: 1-13.

30. Filippo E, Senna A, Bucolieri A, Manno D (2010) Green synthesis of silver nanoparticles with sucrose and maltose: Morphological and structural characterization. Journal of Non-Crystalline Solids 356(6-8): 344-350.

31. Franci G, Falanga A, Galdiero S, Palomba L, Rai M, et al. (2015) Silver nanoparticles as potential antibacterial agents. Molecules 20(5): 8856-8874.

32. Ghaffari-Moghaddam M, Hadi-Dabanlou R, Khajeh M, Rakhshanipour M, Shameli K (2011) Green synthesis of silver nanoparticles using plant extracts. Korean Journal of Chemical Engineering 31: 548-557.

33. Gurunathan S, Han JW, Kwon DN, Kim JH (2014) Enhanced antibacterial and anti-biofilm activities of silver nanoparticles against Gram-negative and Grampositive bacteria. Nanoscale Res Lett 9(1): 373.

34. Gurunathan S, Han JW, Eppakayala V, Jeyaraj M, Kim JH (2013) Cytotoxicity of biologically synthesized silver nanoparticles in MDA-MB-231 human breast cancer cells. Biomed Res Int 2013: 535796.

35. Hariharan D, Thangamuniyandi P, Jegatha Christy A, Vasantharaja R, Selvakumar P (2020) Enhanced photocatalysis and anticancer activity of green hydrothermal synthesized Ag@TiO2 nanoparticles. Journal of Photochemistry and Photobiology B: Biology 202: 111636.

36. Hernández-Morales L, Espinoza-Gómez H, Flores-López ZL, Sotelo-Barrera LE, Núñez-Rivera A, et al. (2019) Study of the green synthesis of silver nanoparticles using a natural extract of dark or white Salvia hispanica L. seeds and their antibacterial application. Applied Surface Science 489: 952-961.

37. Hembram KC, Kumar R, Kandha L, Parhi PK., Kundu CN, et al. (2018) Therapeutic prospective of plant-induced silver nanoparticles: application as antimicrobial and anticancer agent. Artificial Cells, Nanomedicine, and Biotechnology 46: S38-S51.

38. Heydari R (2011) Biological applications of biosynthesized silver nanoparticles through the utilization of plant extracts. Herb Med J 2: 87-95.

39. Hulkoti NI, Taranath TC (2015) Biosynthesis of nanoparticles using microbes-A review. Colloids and Surfaces B: Biointerfaces 121: 474-483.

40. Jeevanandam J, Barhoum A, Chan YS, Dufresne A, Danquah MK (2018) Review on nanoparticles and nanostructured materials: history, sources, toxicity and regulations. Beilstein Journal of Nanotechnology 9: 1050-1074.

41. Jeyaraj M, Gurunathan S, Qasim M, Kang MH, Kim JH (2019) A Comprehensive Review on the Synthesis, Characterization, and Biomedical Application of Platinum Nanoparticles. Nanomaterials Basel, Switzerland) 9(12): 1719.

42. Jorge de Souza TA, Rosa Souza LR, Franchi LP (2019) Silver nanoparticles: An integrated view of green synthesis methods, transformation in the environment and toxicity. Ecotoxicology and Environmental Safety 171: 691-700.

43. Kalpana D, Lee CY (2005) Synthesis and characterizatio n of bactericidal silver nanoparticles using cultural filtrate of simulated microgravity grown Klebsiella pneumoniae. Enzyme and Microbial Technology 52: 151-156.

44. Kashmery HAA (2015) Exploration of a template-directed approach for the synthesis of silver nanoparticles. Dept of Pure and Applied Chemistry. University of Strathclyde, UK.

45. Khanna P, Kaur A, Goyal D (2019) Algae based met allic nanoparticles: Synthesis, characterization and 
applications. Journal of Microbiological Methods 163: 105656.

46. Korbekandi H, Iravani S, Abbasi S (2012) Optimizatio $\mathrm{n}$ of biological synthesis of silver nanoparticles using Lactobacillus casei subsp. casei. Journal of Chemical Technology and Biotechnology 87(7): 932-937.

47. Kumar SV, Bafana AP, Pawar P, Rahman A, Dahoumane SA, et al. (2018) High conversion synthesis of $<10 \mathrm{~nm}$ starch-stabilized silver nanoparticles using microwave technology. Scientific Reports 8: 5106.

48. Kumar V, Singh DK, Mohan S, Gundampati KR, Hasan $H$ (2012) Photoinduced green synthesis of silver nanoparticles using aqueous extract of Physalis angulate and its antibacterial and antioxidant activity. Journal of Environmental Chemical Engineering 5:744-756.

49. Lee SH, Jun BH (2014) Silver Nanoparticles: Synthesis and Application for Nanomedicine. International journal of molecular sciences 20(4): 865.

50. Li G, He D, Qian Y, Guan B, Gao S, et al. (2012) Fungusmediated green synthesis of silver nanoparticles using Aspergillus terreus. International Journal of Molecular Sciences 13(1): 466-476.

51. Maity D, Pattanayak S, Mollick MMR, Rana D, Mondal D, et al. (2016) Green one step morphosynthesis of silver nanoparticles and their antibacterial and anticancerous activities. New Journal of Chemistry 40(3): 2749-2762.

52. Makarov VV, Love AJ, Sinitsyna OV, Makarova SS, Yaminsky IV, et al. (2016) Green Nanotechnologies: Synthesis of Metal Nanoparticles Using Plants. Acta Naturae 6: 35-44.

53. Mashwani ZR, Khan MA, Khan T, Nadhman A (2016) Applications of plant terpenoids in the synthesis of colloidal silver nanoparticles. Advances in Colloid and Interface Science 234: 132-141.

54. Mittal AK, Kaler A, Banerjee UC (2014) Free radical scavenging and antioxidantactivity of silver nanoparticles synthesized from flower extract of Rhododendron dauricum. Nano Biomedicine and Engineering 4: 118124.

55. Mosaviniya M, Kikhavani T, Tanzifi M, Tavakkoli Yaraki M, Tajbakhsh P, et al. (2019) Facile green synthesis of silver nanoparticles using Crocus Haussknechtii Bois bulb extract: catalytic activity and antibacterial properties. Colloid and Interface Science Communications 33: 100211.

56. MubarakAli D, Thajuddin N, Jeganathan K, Gunasekaran
M (2011) Plant extract mediated synthesis of silver and gold nanoparticles and its antibacterial activity against clinically isolated pathogens. Colloids and surfaces B: Biointerfaces 85(2): 360-365.

57. Neiderud CJ (2015) How urbanization affects the epidemiology of emerging infectious diseases. Infection ecology \& epidemiology 5: 27060.

58. Nguyen VT, Vu VT, Nguyen TH, Nguyen TA, Tran VK, et al. (2019) Antibacterial Activity of TiO2-and ZnO-Decorated with Silver Nanoparticles. Journal of Composites Science 3(2): 61 .

59. Otari SV, Patil RM, Ghosh SJ, Thorat ND, Pawar SH (2015) Intracellular synthesis of silver nanoparticle by actinobacteria and its antimicrobial activity. Spectrochimica Acta Part A: Molecular and Biomolecular Spectroscopy 136: 1175-1180.

60. Ovais M, Khalil AT, Ayaz M, Ahmad I, Nethi SK, et al. (2018) Biosynthesis of Metal Nanoparticles via Microbial Enzymes: A Mechanistic Approach. International journal of molecular sciences 19(12): 4100.

61. Owaid NM (2019) Green synthesis of silver nanoparticles by Pleurotus and their bioactivity: Review. Environmental Nanotechnology, Monitoring and Management 12: 100256.

62. Owaid MN, Ibraheem IJ (2017) Mycosynthesis of nanoparticles using edible and medicinal mushrooms. European Journal of Nanomedicine 9: 5-23.

63. Owaid MN, Al-Samedi SSS, Al-Assaffii IAA (2017) Antifungal activity of cultivated oyster mushrooms on various agro-wastes. Summa Phytopathologica 43: 9-13.

64. Owaid MN, Abed AM, Nassar BM (2015) Recycling cardboard wastes to produce blue oyster mushroom Pleurotus ostreatus in Iraq. Emirates Journal of Food and Agriculture 27(7): 537-541.

65. Owaid MN, Nassar BM, Abed AM, Turki AM (2015) Effect of cellulosic matter and container size on cultivation and yield of oyster mushroom Pleurotus ostreatus. Journal of Medicinal Herbs and Ethnomedicine 1(1): 59-63.

66. Owaid MN, Raman J, Lakshmanan H, Al-Saeedi SSS, Sabaratnam V, et al. (2015) Mycosynthesis of silver nanoparticles by Pleurotus cornucopiae var. citrinopileatus and its inhibitory effects against Candida sp. Materials Letters 153: 186-190.

67. Patra JK, Das G, Fraceto LF, Campos E, Rodriguez-Torres $\mathrm{M}$, et al. (2018) Nano based drug delivery systems: 
recent developments and future prospects. Journal of Nanobiotechnology 16(1): 71.

68. Phan HT, Haes AJ (2019) What Does Nanoparticle Stability Mean?. The journal of physical chemistry. C, Nanomaterials and interfaces 123(27): 16495-16507.

69. Prabhu S, Poulose EK (2012) Silver nanoparticles: mechanism of antimicrobial action, synthesis, medical applications, and toxicity effects. International Nano Letters 2(32): 1-12.

70. Prabu J, Johnson I (2015) Plant-mediated biosynthesis and characterization of silver nanoparticles by leaf extracts of Tragia involucrata, Cymbopogon citronella, Solanum verbascifolium and Tylophora ovata. Karbala International Journal of Modern Science 1(4): 237-246.

71. Prestinaci F, Pezzotti P, Pantosti A (2015) Antimicrobial resistance: a global multifaceted phenomenon. Pathogens and global health 109(7): 309-318.

72. Qasim M, Singh BR, Naqvi AH, Paik P, Das D (2015) Silver nanoparticles embedded mesoporous $\mathrm{SiO}_{2}$ nanosphere: an effective anticandidal agent against Candida albicans 077. Nanotechnology 26(28): 285102.

73. Rabiei K, Bekhradnia S, Nabavi SM, Nabavi SF, Ebrahimzadeh MA (2012) Antioxidant activity of polyphenol and ultrasonic extracts from fruits of Crataegus pentagyna subsp. elburensis. Natural Product Research 26(24): 2353-2357.

74. Rafique M, Sadaf I, Rafique MS, Tahir BM (2016) A review on green synthesis of silver nanoparticles and their applications. Artificial Cells 7(7): 1-20.

75. Rajan R, Chandran K, Harper SL, Yun SI, Kalaichelvan PT (2015) Plant extract synthesized silver nanoparticles: An ongoing source of novel biocompatible materials. Industrial Crops and Products 70: 356-373.

76. Ramos AP, Cruz M, Tovani CB, Ciancaglini P (2017) Biomedical applications of nanotechnology. Biophysical reviews 9(2): 79-89.

77. Rheder DT, Guilger M, Bilesky-José N, Germano-Costa T, Pasquoto-Stigliani T, et al. (2018) Synthesis of biogenic silver nanoparticles using Althaea officinalis as reducing agent: evaluation of toxicity and ecotoxicity. Scientific reports 8(1): 12397.

78. Rivas M, Del Valle LJ, Alemán C, Puiggalí J (2019) Peptide Self-Assembly into Hydrogels for Biomedical Applications Related to Hydroxyapatite. Gels 5(1): 14.

79. Roopan SM, Thakur R, Madhumitha RG, Rahuman AA,
Kamaraj C, et al. (2013) Low-cost and eco-friendly phytosynthesis of silver nanoparticles using Cocos nucifera coir extract and its larvicidal activity. Industrial Crops and Products 43: 631-635.

80. Ruíz-Baltazar ÁJ, Reyes-López SY, Silva-Holguin PN, Larrañaga D, Estévez M, Pérez R (2018) Novel biosynthesis of Ag-hydroxyapatite: Structural and spectroscopic characterization. Results in Physics 9: 593-597.

81. Saifuddin NM, Wong CW, Yasumira NAA (2009) Rapid biosynthesis of silver nanoparticles using culture supernatant of bacteria with microwave irradiation. E-Journal of Chemistry 6(1): 61-70.

82. Saravanakumar K, Wang HM (2018) Trichoderma based synthesis of anti-pathogenic silver nanoparticles and their characterization, antioxidant and cytotoxicity properties. Microbial Pathogenesis 114: 269-273.

83. Sathiyamoorthi E, Iskandarani B, Salunke BK, Kim BS (2018) Biomedical potential of silver nanoparticles biosynthesized using gallnut extract. Green Materials $6(2): 48-57$.

84. Saxena A, Tripathi RM, Zafar F, Singh P (2014) Green synthesis of silver nanoparticles using aqueous solution of Ficus benghalensis leaf extract and characterization of their antibacterial activity. Materials Letters 67(1): 9194.

85. Saxena J, Sharma PK, Sharma MM, Singh A (2014) Process optimization for green synthesis of silver nanoparticles by Sclerotinia sclerotiorum MTCC 8785 and evaluation of its antibacterial properties. SpringerPlus 5(1): 861868.

86. Seetharaman PK, Chandrasekaran R, Gnanasekar S, Chandrakasan G, Gupta M, et al. (2018) Antimicrobial and larvicidal activity of eco-friendly silver nanoparticles synthesized from endophytic fungi Phomopsis liquidambaris. Biocatalysis and Agricultural Biotechnology 16: 22-30.

87. Sekan AS, Myronycheva OS, Karlsson O, Gryganskyi AP, Blume Y (2019) Green potential of Pleurotus spp. in biotechnology. PeerJ 7: e6664.

88. Shah M, Fawcett D, Sharma S, Tripathy SK, Poinern G (2015) Green Synthesis of Metallic Nanoparticles via Biological Entities. Materials 8(11): 7278-7308.

89. Sharma G, Nam JS, Sharma AR, Lee SS (2018) Antimicrobial Potential of Silver Nanoparticles Synthesized Using Medicinal Herb Coptidis rhizome. 
Molecules 23: 2268.

90. Sharma G, Kumar A, Sharma S, Naushad M, Prakash Dwivedi R, et al. (2019) Novel development of nanoparticles to bimetallic nanoparticles and their composites: A review. Journal of King Saud University Science 31(2): 257-269.

91. Siddiqi KS, Husen A, Rao R (2018) A review on biosynthesis of silver nanoparticles and their biocidal properties. Journal of nanobiotechnology 16(1): 14.

92. Singh J, Dutta T, Kim KH, Rawat M, Samddar P, et al. (2018) 'Green' synthesis of metals and their oxide nanoparticles: applications for environmental remediation. Journal of nanobiotechnology 16(1): 84 .

93. Singh P, Kim YJ, Singh H, Wang C, Hwang KH, et al. (2015) Biosynthesis, characterization, and antimicrobial applications of silver nanoparticles. International journal of nanomedicine 10: 2567-2577.

94. Siva Kumar K, Kumar G, Prokhorov E, Luna-Bárcenas G, Buitron G, etal. (2014) Exploitation of anaerobic enriched mixed bacteria for the silver and gold nanoparticles synthesis. Colloids and Surfaces A: Physicochemical and Engineering Aspects 462: 264-270.

95. Sravani M, Kumar MK (2018) Synthesis of TiO2-Ag Nanocomposites via Green Route for Dye Degradation and Antimicrobial Studies. International Journal for Research in Applied Science \& Engineering Technology $6(1)$.

96. Su Y, Shi B, Liao S, Zhao J, Chen L, et al. (2016) Silver Nanoparticles/N-Doped Carbon-Dots Nanocomposites Derived from Siraitia Grosvenorii and Its Logic Gate and Surface-Enhanced Raman Scattering Characteristics. ACS Sustainable Chem Eng 4(3): 1728-1735.

97. Sundari TM, Anand AAP, Jenifer P (2018) Bioprospection of Basidiomycetes and molecular phylogenetic analysis using internal transcribed spacer and 5.8S rRNA gene sequence. Science Reports 8: 10720.

98. Tarannum N, Divya D, Gautam YK (2019) Facile green synthesis and applications of silver nanoparticles: a state-of-the-art review. RSC Advances 9(60): 3492634948.

99. Tavakoli F, Badiei A, Ghasemi JB (2019) Novel and ecofriendly synthesis of Ag-TiO2-G photocatalyst and investigate the effect of graphene in photodegradation of an organic pollutant in water. J Water Environ Nanotechnol 4(1): 31-39.

100. Thangavelu RM, Ganapathy R, Ramasamy P,
Krishnan K (2018) Fabrication of virus metal hybrid nanomaterials: An ideal reference for bio semiconductor. Arabian Journal of Chemistry 13(1): 2750-2765.

101. Thiruvengadam M, Rajakumar G, Chung IM (2018) Nanotechnology: current uses and future applications in the food industry. 3 Biotech 8(1): 74.

102. Tian Y, Wang F, Liu Y, Pang F, Zhang X (2014) Green synthesis of silver nanoparticles on nitrogendoped graphene for hydrogen peroxide detection. Electrochimica Acta 146: 646-653.

103. Tippayawat P, Phromviyo N, Boueroy P, Chompoosor A (2016) Green synthesis of silver nanoparticles in aloe vera plant extract prepared by a hydrothermal method and their synergistic antibacterial activity. Peer J 4: e2589.

104. Vamanu E, Ene M, Bita B, Lonescu C, Cracium L, et al. (2018) In vitro human microbiota response to exposure to silver nanoparticles biosynthesized with mushroom extract. Nutrients 2018 10: 607.

105. Vasimalai N, Sheeba G, John SA (2012) Ultrasensitive fluorescence-quenched chemosensor for $\mathrm{Hg}$ in aqueous solution based on mercaptothiadiazole capped silver nanoparticles. Journal of Hazardous Materials 213-214: 193-199.

106. Veerasamy R, Xin TZ, Gunasagaran S, Xiang TFW, Yang EFC, et al. (2011) Biosynthesis of silver nanoparticles using mangosteen leaf extract and evaluation of their antimicrobial activities. Journal of Saudi Chemical Society 15: 113-120.

107. Vigneshwaran N, Ashtaputre NM, Varadarajan PV, Nachane RP, Paralikar KM, et al. (2007) Biological synthesis of silver nanoparticles using the fungus Aspergillus flavus. Materials Letters 61(6): 1413-1418.

108. Wang J, Wang L, Lou GH, Zeng HR, Hu J, et al. (2019) Coptidis Rhizoma: a comprehensive review of its traditi onal uses, botany, phytochemistry, pharmacology and to xicology. Pharmaceutical biology 57(1): 193-225.

109. Wang C, Kim JY, Singh P, Mathiyalagan R, Jin Y, et al. (2016) Green synthesis of silver nanoparticles by Bacillus methylotrophicus, and their antimicrobial activity. Artificial Cells, Nanomedicine, and Biotechnology 44(4): 1127-1132.

110. Wang Z, Zhang J, Ekman JM, Kenis PJA, Lu Y (2010) DNA-mediated control of metal nanoparticle shape: onepot synthesis and cellular uptake of highly stable and functional gold nanoflowers. Nano Letters 10(5): 1886- 
1891.

111. Welton T (2015) Solvents and sustainable chemistr y. Proceedings. Mathematical, physical, and engineering sciences 471(2183): 20150502.

112. Xie Y, Kocaefe D, Chen C, Kocaefe Y (2016) Review of Research on Template Methods in Preparation of Nanomaterials. Journal of Nanomaterials 2016: 2302595.

113. Zahir AA, Chauhan IS, Bagavan A, Kamaraj C, Elango G, et al. (2015) Green Synthesis of Silver and Titanium Dioxide Nanoparticles Using Euphorbia prostrata Extract Shows Shift from Apoptosis to G0/G1 Arrest followed by Necrotic Cell Death in Leishmania donovani. Antimicrobial Agents and Chemotherapy 59(8): 4782-
4799.

114. Zare M, Namratha K, Alghamdi S, Mohammad YHE, Hezam A, et al. (2019) Novel Green Biomimetic Approach for Synthesis of $\mathrm{ZnO}-\mathrm{Ag}$ Nanocomposite; Antimicrobial Activity against Food-borne Pathogen, Biocompatibility and Solar Photocatalysis. Scientific Reports 9: 8303.

115. Zhang Y, Dong Y, Zhou J, Li X, Wang F (2018) Application of Plant Viruses as a Biotemplate for Nanomaterial Fabrication. Molecules 23(9): 2311.

116. Zhang XF, Liu ZG, Shen W, Gurunathan S (2016) Silver Nanoparticles: Synthesis, Characterization, Properties, Applications, and Therapeutic Approaches. International journal of molecular sciences 17(9): 1534. 